\title{
Kesiapan Guru dalam Mengembangkan Modul Berbasis STEM untuk Mendukung Pembelajaran di Abad 21
}

\author{
Nana Diana ${ }^{1}$, Turmudi ${ }^{2}$ \\ ${ }^{1}$ Program Studi Pendidikan Matematika, Sekolah Pascasarjana, Universitas Pendidikan Indonesia \\ ${ }^{2}$ Departemen Pendidikan Matematika, Sekolah Pascasarjana, Universitas Pendidikan Indonesia \\ E-mail: nanadiana@upi.edu ${ }^{1}$
}

\begin{abstract}
Abstrak
Kemampuan siswa yang diharapkan saat ini tidak hanya sekedar menghafalkan konsep suatu pembelajaran, namun juga harus mampu menyusun sendiri pengetahuannya serta bisa menggunakan pengetahuan tersebut untuk menyelesaikan permasalahan kontekstual. Kehadiran pendekatan pembelajaran STEM, yang merupakan integrasi empat pengetahuan berupa Science, Technology, Engineering dan Mathematics menjadi salah satu inovasi yang tepat bagi siswa untuk membangun pengetahuannya sendiri. Namun demikian, terdapat beberapa kendala yang terjadi untuk menerapkan pembelajaran berbasis STEM, di antaranya terkait dengan persiapan pembelajaran STEM. Oleh karena itu, penelitian ini bertujuan untuk mengetahui lebih lanjut kesiapan guru-guru di Indonesia terhadap pembelajaran STEM, ditinjau dari pengetahuan mereka terhadap STEM dan pengalaman menyusun modul berbasis STEM. Metode yang digunakan dalam penelitian ini adalah metode eksploratori. Penelitian ini dilaksanakan secara online dengan menggunakan questionnaire melalui google form. Beberapa guru juga diwawancara untuk mendapatkan konfirmasi atas jawaban yang mereka cantumkan di google form. Subjek dalam penelitian ini terdiri dari 54 orang guru Matematika dan IPA. Setelah data diperoleh, data selanjutnya dianalisis secara kualitatif. Berdasarkan penelitian ini diketahui bahwa sebagian besar guru yang mengikuti survey sederhana ini belum memiliki pengetahuan memadai terkait STEM, sehingga guru masih kesulitan dalam menyusun modul berbasis STEM.
\end{abstract}

Kata Kunci: guru matematika dan IPA, kesiapan guru, modul pembelajaran, pendekatan STEM.

\section{Teachers' Readiness in Developing STEM-based Module to Support Teaching and Learning in the $21^{\text {st }}$ Century}

\begin{abstract}
Nowadays, students' expected comprehensions are not only capable in memorizing formal concepts, but also capable in constructing their knowledge in solving contextual problems. The presence of the STEM approach, which is the integration of four knowledge including Science, Technology, Engineering and Mathematics, considered as one of the appropriate innovations for students in establishing their own knowledge. However, there are several problems that occur in implementing STEM approach in learning, including the preparation for STEM learning. Hence, this study aims to investigate the readiness of teachers in Indonesia to implement STEM learning, in terms of their knowledge about STEM and experience in arranging STEM-based modules. This research was conducted online using a questionnaire which was distributed through google form. Several teachers were also interviewed to get confirmation of their answers on the google form. The subjects in this study consisted of 54 Mathematics and Science teachers in junior high school. After the data was obtained, the data were analyzed qualitatively. Based on this research, it is known that most of the teachers who participated in this study did not have adequate knowledge regarding STEM, so that teachers were struggling in developing STEM-based modules.
\end{abstract}

Keywords: learning module, mathematics and science teachers, STEM approach, teachers' readiness. 


\section{PENDAHULUAN}

Perkembangan pengetahuan dari waktu ke waktu menuntut adanya penyesuaian kurikulum untuk mempertahankan keberlangsungan dan efektifitas penerapannya dengan kondisi terkini. Misalnya dalam matematika, perkembangan pengetahuan dari waktu ke waktu terus terjadi. Matematika tidak hanya dipandang sebagai pengetahuan yang menekankan kalkulasi dan terpisah dari hal-hal kontekstual, melainkan pengetahuan harus disusun dari kegiatan nyata di sekeliling pembelajar. Oleh karena itu, tujuan pendidikan matematika yang diharapkan saat ini adalah terbentuknya kemampuan siswa untuk mengimplementasikan matematika agar mampu menyelesaikan permasalahan kontekstual (Gravemeijer et al., 2017).

Kebutuhan pengetahuan di abad ke-21 yang semakin pesat menuntut adanya perkembangan proses untuk membentuk suatu pengetahuan. Oleh karena itu, guru perlu menginisiasi proses pembelajaran yang mendukung siswa untuk mampu beradaptasi dengan tuntutan pengetahuan yang dibutuhkan di abad ke-21 (Teo, 2019). Siswa perlu berupaya untuk mengembangkan pengetahuannya dengan memanfaatkan segala potensi yang mereka miliki. Di abad ke-21 juga, siswa juga perlu menjadi lebih giat untuk mengusahakan mendapatkan pengetahuan baru. Lebih lanjut, beberapa penelitian menunjukkan bahwa STEM memiliki hubungan yang positif terhadap pembelajaran di yang sesuai dengan abad ke-21(Kan \& Murat, 2018)

STEM akan membantu siswa untuk menyusun pengetahuannya sendiri dengan cara mengintegrasikan beberapa pengetahuan dalam satu project. STEM yang merupakan integrasi pengetahuan dari empat pengetahuan utama yaitu Science, Technology, Engineering dan Mathematics. Dalam perkembangannya, STEM juga dikombinasikan dengan pengetahuan lain misalnya seperti seni (Art) menjadi STEAM ataupun dengan Kesehatan (Medicine) dengan sebutan STEMM. STEM sendiri dikembangkan oleh National Science Foundation di Amerika Serikat di tahun 1990an. Pembelajaran dengan STEM menuntut siswa untuk melakukan interaksi dan menciptakan investigasi dalam memperoleh pengetahuan (Tofel-Grehl \& Callahan, 2014). Oleh karena itu, pembelajaran dengan pendekatan STEM menjadi salah satu solusi untuk meningkatkan inovasi dalam pembelajaran matematika yang sesuai untuk kebutuhan saat ini.

Urgensi pembelajaran berbasis STEM di antaranya untuk (1) meningkatkan kemampuan korelasi matematis siswa (Ni et al., 2018), (2) meningkatkan kemampuan berpikir kritis siswa (Hafni et al., 2020) dan (Rosikhoh et al., 2019), (3) meningkatkan kemampuan berpikir kreatif siswa (Puspandari \& Supraman, 2018), (4) meningkatkan kemampuan siswa berpikir logis dan sistematis (Anggraini \& Huzaifah, 2017) dan (5) meningkatkan kemampuan pemecahan masalah siswa (Dewi et al., 2018). Berdasarkan penemuan tersebut, diketahui bahwa pembelajaran dengan STEM memberikan dampak positif bagi siswa.

Pembelajaran matematika agar efektif memerlukan modul yang sesuai. Oleh karena itu, pengembangan modul dalam pembelajaran matematika menjadi sangat penting. Terlebih karena buku teks pelajaran yang tersedia saat ini belum semua memenuhi kriteria proses pembelajaran yang sesuai dengan abad ke-21 (Kristanto \& Santoso, 2020). Lebih lanjut, pengembangan modul dalam pembelajaran matematika sangat penting untuk mendukung proses pembelajaran berbasis STEM. Beberapa penelitian terdahulu juga menunjukkan bahwa pengembangan modul pembelajaran berbasis STEM memiliki pengaruh yang baik untuk menyelenggarakan pembelajaran STEM yang efektif (Gustiani et al., 2017). Selanjutnya, penelitian lain juga menunjukkan bahwa modul pembelajaran berbasis STEM yang memenuhi standar pelaksanaan adalah harus valid, praktis digunakan dan efektif. Namun demikian, berbagai kendala yang dimiliki guru menjadi penyebab tidak siapnya mereka untuk mengimplementasikan STEM dalam proses pembelajaran. Oleh karena itu, tujuan dari penelitian ini adalah untuk mengetahui kesiapan guru Matematika dan IPA di sekolah menengah pertama dalam menyusun modul pembelajaran berbasis STEM.

\section{METODE}

Penelitian ini menggunakan metode eksploratori, dimana data dikumpulkan dengan menggunakan questionnaire yang disebarkan secara online dengan menggunakan google form. 
Wawancara melalui telepon selanjutnya juga dilakukan untuk mendapatkan konfirmasi dari jawaban yang diberikan responden. Pertanyaan yang tercantum dalam kuesioner terbuka, sebagai berikut:

1. Apakah Bapak/Ibu mengetahui tentang pembelajaran berbasis STEM?

2. Bagaimana pendapat Bapak/Ibu terhadap pembelajaran berbasis STEM?

3. Apakah pembelajaran berbasis STEM sudah pernah diterapkan di sekolah Bapak/lbu?

4. Apakah Bapak/Ibu pernah membuat modul pembelajaran berbasis STEM?

5. Jika pernah, pada materi apakah Bapak/Ibu membuat modul tersebut?

Proses pengumpulan data dilakukan selama tujuh hari sejak tanggal 28 Desember 2020 hingga tanggal 3 Januari 2021. Questionnaire tersebut disebarkan ke beberapa guru yang mengajar Matematika dan IPA di sekolah menengah pertama. Berdasarkan tanggapan yang diterima setelah questionnaire dilengkapi, diketahui jumlah data yang masuk adalah 56 responden, namun yang sesuai kriteria hanya 54 responden karena dua responden yang lain tidak mengisi pertanyaan di dalam kuesioner terbuka secara lengkap. Guru yang menjadi responden memiliki riwayat pendidikan berbeda, yaitu dengan ketentuan pendidikan terakhir S1 sebanyak 47 orang, S2 sebanyak 6 orang dan S3 sebanyak 1 orang. Secara keseluruhan, guru terdiri dari 35 guru dari SMP negeri dan 19 guru dari SMP swasta dan didominasi oleh 48 orang guru matematika, 3 orang guru biologi, 2 orang guru kimia dan 1 orang guru IPA. Usia guru yang menjadi responden mulai dari 23 tahun hingga 58 tahun dengan pengalaman mengajarkan ditunjukkan dalam table.1. Data yang diperoleh selanjutnya diklasifikasikan sesuai dengan kategori untuk selanjutnya dianalisis secara kualitatif.

Tabel 1. Pengalaman mengajar guru responden

\begin{tabular}{lll}
\hline Pengalaman mengajar & Jumlah Guru & Persentase \\
\hline Kurang dari 5 tahun & 32 orang & $61,1 \%$ \\
5 sampai 10 tahun & 11 orang & $18,5 \%$ \\
10 sampai 15 tahun & 2 orang & $5,6 \%$ \\
Lebih dari 15 tahun & 8 orang & $14,8 \%$ \\
\hline
\end{tabular}

\section{HASIL DAN PEMBAHASAN}

Pembelajaran yang berbasis STEM merupakan salah satu inovasi pembelajaran yang diprediksikan menjadi solusi yang tepat untuk menyiasati kebutuhan pengetahuan di abad ke-21 dan revolusi industry 4.0. Namun demikian, karena masih tergolong baru untuk pembelajaran di Indonesia, serta belum adanya regulasi khusus di dalam kurikulum saat ini, pembelajaran dengan pendekatan STEM masih sulit untuk diterapkan. Berbagai kendala dalam penerapan STEM dalam pembelajaran telah diselidiki melalui serangkaian penelitian, di antaranya (1) ketersediaan waktu yang terbatas, (2) keterbatasan untuk bekerja sama dengan guru/ahli dalam bidang lain yang terkait STEM, (3) kesulitan menemukan tim kerja, (4) kurang mendapatkan dukungan dari orang tua murid, (5) kompetensi guru yang belum memadai dalam menyiapkan material yang dibutuhkan dalam pembelajaran STEM, (6) kesulitan mendapatkan biaya untuk membeli peralatan yang dibutuhkan dalam STEM, (7) kurangnya fasilitas yang tersedia di sekolah dan (8) guru belum terbiasa dengan rencana pembelajaran yang berbasis STEM (Winangun \& Kurniawan, 2019). Penelitian yang lain juga menunjukkan bahwa permasalahan yang dialami guru dalam pembelajaran berbasis STEM antara lain (1) guru belum memahami makna pembelajaran berbasis STEM secara detail, (2) terbatasnya waktu yang tersedia, sedangkan pembelajaran STEM membutuhkan waktu yang lumayan lama, (3) ketertarikan dan keterlibatan siswa dalam pembelajaran berbasis STEM masih rendah dan (4) pengalaman guru dalam pembelajaran berbasis STEM masih sangat sedikit sehingga membutuhkan pelatihan lebih lanjut (Susilo \& Sudrajat, A., 2020). Kesulitan-kesulitan tersebut menjadi tantangan sekaligus membutuhkan solusi untuk meminimalisirkannya.

Meskipun terlihat sulit diterapkan, namun penelitian lain juga menunjukkan bahwa pembelajaran dengan pendekatan STEM nyatanya memberikan dampak yang sangat positif terhadap pembelajaran yang dibutuhkan saat ini. Sebagai pendekatan yang mengintegrasikan empat pengetahuan atau lebih dalam suatu proses pembelajaran, STEM terbukti dapat menyelesaikan permasalahan kontekstual yang erat dengan kondisi sebenarnya yang dialami siswa (Hafni et al., 2020). Lebih lanjut, pembelajaran STEM juga dipilih dengan beberapa alasan, di antaranya (1) kesempatan untuk menyesuaikan 
pengetahuan yang dibutuhkan dalam STEM, (2) implementasi STEM sebenarnya sederhana, mudah, tidak membutuhkan waktu dan biaya yang begitu besar, (3) pembelajaran STEM lebih efektif untuk memaksimalkan potensi siswa untuk memahami dan menciptakan pengetahuannya dan (4) menambah nilai dalam proses pembelajaran melalui kombinasi beberapa pengetahuan (Bozkurt \& Özyurt, 2019). Kelebihan tersebut akhirnya menjadi pendorong agar pembelajaran berbasis STEM tetap diterapkan, termasuk di Indonesia, meskipun dengan beberapa tantangan.

Penelitian-penelitian terdahulu juga menunjukkan bahwa ada beberapa upaya yang bisa dilakukan untuk menjadi solusi agar proses pembelajaran berbasis STEM bisa berjalan. salah satu penelitian terkait mengungkapkan bahwa upaya yang bisa dilakukan di antaranya otoritas dalam bidang pendidikan perlu membangun kesadaran bagi guru tentang pentingnya STEM, memberikan pelatihan agar guru memiliki keahlian untuk mengajarkan pembelajaran berbasis STEM dan juga menyediakan fasilitas yang memadai agar proses pembelajaran berlangsung sesuai dengan yang diharapkan (Ramli \& Talib, 2017). Guru juga harus dibantu dengan dipersiapkan pelatihan untuk mengembangkan profesionalisme, kemampuan pedagogi dan kemampuan memahami kurikulum agar benar-benar siap untuk mengimplementasikan STEM (Geng et al., 2019) karena selama ini guru juga terlihat ragu apakah mereka mampu atau tidak untuk menerapkan STEM dalam pembelajaran (Shernoff et al., 2017). Lebih lanjut, untuk mengatasi permasalahan yang terkait dengan fasilitas dan biaya, guru diharapkan dapat melakukan modifikasi pembelajaran STEM agar dapat diterapkan sesuai dengan kondisi yang ada (Milaturrahmah et al., 2017). Antusias guru-guru untuk mengembangkan pembelajaran berbasis STEM juga terlihat dari pengembangan media belajar yang telah berjalan hingga saat ini, di antaranya buku siswa berbasis STEM (Nessa et al., 2017), lembar kerja siswa berbasis STEM (Setiawaty et al., 2019) dan modul berbasis STEM (Alfika et al., 2019).

Pengembangan modul berbasis STEM terus dilaksanakan untuk memudahkan guru mengimplementasikan pembelajaran sesuai dengan tuntutan kondisi saat ini. Berdasarkan salah satu penelitian tentang pengembangan modul matematika berbasis STEM dengan mengadopsi model Borg and Gall, diketahui bahwa kelayakan modul berdasarkan penilaian para ahli tergolong sangat layak dan berdasarkan uji coba kepada siswa dan guru, modul tersebut juga dikategorikan menarik (Utami et al., 2018). Studi terkait lainnya juga menunjukkan bahwa kesiapan dan respon siswa terhadap materi pembelajaran berbasis STEM tergolong sangat baik dan dapat digunakan secara efektif untuk melangsungkan pembelajaran STEM (Gustiani et al., 2017). Selanjutnya, peneliti lain juga mengemukakan bahwa modul pembelajaran yang dikembangkan dengan pendekatan STEM di dalamnya terbukti mampu meningkatkan kemampuan berpikir kreatif siswa (Retnowati et al., 2020). Oleh karena itu, pengembangan modul pembelajaran matematika berbasis STEM dapat menjadi solusi untuk menyongsong kebutuhan pengetahuan siswa saat ini.

\section{Pengetahuan guru terhadap STEM}

Berdasarkan hasil yang diperoleh dari online questionnaire diketahui jumlah guru yang belum mengetahui tentang STEM adalah sebanyak 19 orang guru. Sementara itu, sebanyak 35 orang guru telah mengetahui tentang STEM. hal ini menunjukkan bahwa 64,8\% guru yang menjadi responden telah mengetahui tentang STEM. Hal ini menjukkan bahwa sebagian besar guru SMP yang mengajar matematika dan IPA telah mengetahui tentang STEM, namun untuk menggali lebih mendalam, maka perlu diketahui lebih lanjut pemahaman awal yang telah dimiliki guru tentang STEM. Jika ditinjau dari lamanya guru mengajar, pada tiap kategori terdapat persentase jumlah guru yang belum mengetahui tentang STEM, diantaranya (1) sebanyak $34 \%$ guru yang mengajar kurang dari lima tahun belum mengetahui tentang STEM, (2) sebanyak 36\% guru yang mengajar antara 5 sampai 10 tahun belum mengetahui tentang STEM, (3) sebanyak 50\% guru yang mengajar selama 10 sampau 15 tahun belum mengetahui tentang STEM dan (4) sebanyak 38\% guru yang mengajar lebih dari 15 tahun juga belum mengetahui tentang STEM. Kondisi ini menujukkan bahwa guru dengan durasi mengajar yang berbedabeda memiliki representasi guru yang belum memiliki pengetahuan tentang STEM.

\section{Pemahaman guru terhadap STEM}

Berdasarkan hasil dari kuesioner dari responden yang terdiri dari 54 orang guru Matematika dan IPA di sekolah menengah pertama, diketahui sebanyak 18 orang guru $(33,3 \%)$ sudah mengetahui tentang pembelajaran berbasis STEM, namun sisanya, 36 orang guru $(67,7 \%)$ belum mengetahui tentang STEM. 
Namun demikian, pengetahuan guru terhadap STEM masih didominasi oleh pengetahuan yang terkait dengan kepanjangan STEM itu sendiri atau sekedar pembelajaran yang mengintegrasikan empat bidang ilmu yaitu Science, Technology, Engineering dan Mathematics. Temuan seperti ini juga pernah terjadi dalam penelitian lain, di mana guru hanya memahami STEM berdasarkan kepanjangannya, tanpa mengetahui penjelasan yang lebih lanjut tentang STEM (Ramli \& Talib, 2017). Ada juga guru yang menjawab seperti berikut: "Siswa diberikan sebuah permasalah dimana permasalahan tersebut nantinya dapat diselesaikan dengan aspek-aspek yang terdapat dalam STEM yaitu science, technology, engineering dan mathematics", namun demikian, jawaban tersebut belum menunjukkan pemahaman yang memadai bagi seorang guru untuk menerapkan pembelajaran berbasis STEM.

Ada juga guru yang mengungkapkan pemahamannya tentang STEM sebagai berikut: $\mathrm{T}_{15}$ : "Berdasarkan penelitian dari beberapa tokoh yang pernah dilakukan di sekolah tempat saya mengajar, pembelajaran berbasis stem lebih mengacu pada penggunaan sains teknologi, engginering dan perhitungan matematika dalam proses pembelajaran. Peserta didik juga dibimbing untuk menghasilkan suatu produk yang bisa membuat mereka lebih memahami materi yang sedang dipelajari”. Guru tersebut merupakan guru muda berusia 24 tahun dengan pengalaman mengajar kurang dari lima tahun dan pernah menyaksikan proses pembelajaran berbasis STEM. Namun demikian, berdasarkan konfirmasi lebih lanjut melalui wawancara, ia mengungkapkan bahwa penerapan STEM yang pernah dilakukan di sekolahnya hanya sebatas proses penelitian yang dilakukan oleh peneliti tertentu. Penerapan STEM juga sulit dilaksanakan di sekolahnya karena kurangnya dukungan dari pihak sekolah. Hal ini juga sejalan dengan penelitian lainnya yang menunjukkan adanya kesulitan menerapkan STEM karena kurangnya dukungan dari otoritas pendidikan, misalnya kepala sekolah (Ramli \& Talib, 2017).

Responden lain yang menunjukkan pemahaman yang baik terhadap STEM yaitu $\mathrm{T}_{31}$, ia mengungkapkan "STEM adalah sebuah pendekatan pembelajaran terpadu yang mendorong siswa untuk berpikir lebih luas tentang masalah di dunia nyata. STEAM juga mendukung pengalaman belajar yang berarti dan pemecahan masalah, dan berpendapat bahwa sains, teknologi, teknik, dan matematika saling terkait". Namun demikian, di sekolahnya juga belum mengimplementasikan STEM. oleh karena itu, guru tersebut juga belum memiliki pengalaman dalam mengembangkan modul berbasis STEM.

\section{Implementasi STEM di Sekolah Guru Responden}

Berdasarkan data yang diperoleh dari responden melalui google form, diketahui bahwa mayoritas guru yang mengisi questionnaire belum pernah mengimplementasikan pembelajaran STEM di sekolah mereka, yaitu seperti ditunjukkan oleh gambar 1.
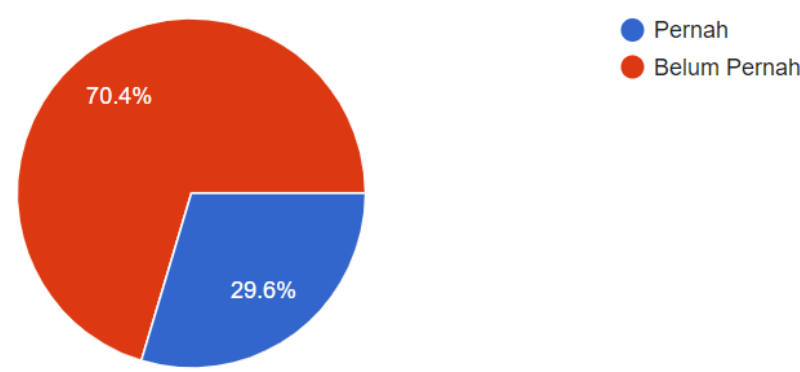

Gambar 1. Persentase guru yang menerapkan STEM dan yang belum menerapkannya

Berdasarkan gambar 1, diketahui bahwa terdapat 40,8\% selisih antara guru yang belum pernah menerapkan STEM dalam pembelajaran dengan yang telah menerapkannya. Hal ini mengisyaratkan bahwa kesiapan guru dalam menyusun modul berbasis STEM dalam pembelajaran masih rendah, namun sudah terlihat ada. Sehingga di kemudian hari, potensi-potensi guru yang telah menerapkannya perlu ditingkatkan sedangkan guru yang belum menerapkannya perlu diberi pelatihan. Hal ini mengingat bahwa ada penelitian yang mengungkapkan bahwa guru membutuhkan pelatihan terhadap keterampilan dan kemampuan mereka agar mampu menerapkan STEM dalam pembelajaran (Susilo \& Sudrajat, A., 2020)(Ramli \& Talib, 2017). Oleh karena itu, diperlukan upaya serius agar guru mendapatkan pelatihan yang memadai agar potensinya dapat dioptimalkan dalam mengembangkan modul berbasis STEM.

Berdasarkan wawancara yang dilakukan dengan guru $T_{1}$ tentang hambatan yang terjadi dalam pembelajaran berbasis STEM, guru tersebut mengungkapkan bahwa "kendala yang di alami, 
diantaranya: (1) kurangnya kemauan guru guru untuk bersatu dan berinovasi untuk menjalankan suatu program salah satunya STEM, (2) fasilitas yang masih minim dan (3) masih belum kuat dalam mengetahuan dasar mengenai STEM". Kendala-kendala tersebut tentunya juga pernah ditemukan dalam penelitian sebelumnya oleh Winangun and Kurniawan (2019). Oleh karena itu, diperlukan juga upaya serius untuk mengatasi kendala-kendala yang dialami guru dalam menerapkan pembelajaran berbasis STEM.

\section{Pengalaman guru menyusun modul STEM}

Pengalaman guru dalan menyusun modul berbasis STEM berdasarkan data yang diperoleh dari online questionnaire menunjukkah hasil yang belum memuaskan. Dari 54 orang guru responden, hanya 7 orang guru yang pernah menyusun modul STEM. Artinya, baru terdapat $13 \%$ dari seluruh subjek yang memiliki pengalaman menyusun modul. Guru-guru yang pernah menyusun modul tersebut terdiri dari 4 orang guru SMP negeri dan 3 orang guru SMP swasta. Guru-guru tersebut memiliki pengalaman mengajar yang berbeda-beda, diantaranya, sebanyak lima orang mengajar kurang dari lima tahun, satu orang mengajar selama 5 sampai 10 tahun dan satu orang lainnya mengajar lebih dari 15 tahun. Artinya, penyusunan modul berbasis STEM lebih didominasi oleh guru-guru baru dengan pengalaman mengajar yang belum terlalu lama.

\section{Modul STEM yang pernah disusun oleh guru}

Meskipun jumlah guru yang pernah menyusun modul berbasis STEM masih sangat sedikit, namun penemuan ini menunjukkan bahwa saat ini sudah ada guru yang mulai membuat modul pembelajaran sebagai inovasi dalam pembelajaran di abad 21. Jika pengembangan modul ini dilanjutkan dan terus ditingkatkan, maka akan semakin banyak guru yang siap untuk menyelenggarakan pembelajaran yang sesuai dengan tuntutan abad 21. Selanjutnya, berdasarkan data yang diperoleh, untuk saat ini ada beberapa responden yang telah mengembangkan modul pembelajaran berbasis STEM, dengan mata pelajaran inti dan topik yang berbeda-beda. Modul-modul tersebut di antaranya tentang (1) interaksi makhluk hidup (IPA), (2) Kesebangunan dan kekongruenan, perbandingan volume kerucut bola tabung sesuai dengan percobaan Archimedes (Matematika), (3) pencemaran lingkungan (IPA) dan logaritma dan eksponen (matematika). Penemuan ini menunjukkan bahwa semangat guru untuk mengembangkan modul pembelajaran berbasis STEM saat sudah mulai ada, namun perlu peningkatan dan bimbingan serius agar guru lebih bisa mengembangkannya di masa mendatang.

\section{SIMPULAN}

Pembelajaran berbasis STEM merupakan inovasi yang tepat untuk dikembangkan saat ini agar proses pembelajaran yang berlangsung bisa menyesuaikan dengan kebutuhan siswa di abad ke- 21 . Namun, dalam pelaksanaannya, pembelajaran STEM masih mengalami berbagai kendala, misalnya terkait dengan kemampuan guru, ketersediaan waktu, ketersediaan fasilitas dan kendala teknis lainnya. Oleh karena itu, guru perlu mendapatkan suatu pemahaman yang memadai agar proses pembelajaran berbasis STEM bisa dilaksanakan sesuai yang diharapkan. Dalam rangka mewujudkan hal tersebut juga, guru perlu dimotivasi lebih lanjut untuk membuat modul pembelajaran berbasis STEM. Pembuatan modul ini bertujuan agar proses pembelajaran menjadi lebih terarah dan dapat mencapai tujuan pembelajaran yang diharapkan. Berdasarkan penelitian ini, masih sedikit guru yang mengetahui tentang STEM, sehingga menyebabkan pengalaman guru dalam mengembangkan modul berbasis STEM juga masih sangat rendah. Oleh karena itu, diperlukan upaya lanjutan yang serius untuk membantu guru dalam mempersiapkan proses pembelajaran berbasis STEM, di antaranya dengan membuat modul pembelajaran berbasis STEM.

\section{DAFTAR PUSTAKA}

Alfika, Z. A., Mayasari, T., \& Kurniadi, E. (2019). Modul STEM Berbasis Pemecahan Masalah dengan Tema Rumah Dome. Jurnal Pendidikan Fisika, 7(1), 93. https://doi.org/10.24127/jpf.v7i1.1566

Anggraini, F. I., \& Huzaifah, S. (2017). Implementasi STEM dalam Pembelajaran IPA di Sekolah Menengah Pertama. Program Studi Pendidikan Biologi Fakultas Keguruan dan Ilmu Pendidikan Universitas Sriwijaya, 1998, 722-731. 
Bozkurt, A., \& Özyurt, M. (2019). Investigate the Reflective Evaluations of Prospective Teacher on STEM Education, Based on Their Experiences with Planning and Implementing STEM Activities. Malaysian Online Journal of Educational Technology, 7(4), 81-97. https://doi.org/10.17220/mojet.2019.04.006

Dewi, M., Kaniawati, I., \& Suwarma, I. R. (2018). Penerapan Pembelajaran Fisika Menggunakan Pendekatan STEM untuk Meningkatkan Kemampuan Memecahkan Masalah Siswa pada Materi Listrik Dinamis. Quantum: Seminar Nasional Fisika, dan Pendidikan Fisika, O(0), 381-385. http://seminar.uad.ac.id/index.php/quantum/article/view/287

Geng, J., Jong, M. S. Y., \& Chai, C. S. (2019). Hong Kong Teachers' Self-efficacy and Concerns about STEM Education. Asia-Pacific Education Researcher, 28(1), 35-45. https://doi.org/10.1007/s40299-018-0414-1

Gravemeijer, K., Stephan, M., Julie, C., Lin, F. L., \& Ohtani, M. (2017). What Mathematics Education May Prepare Students for the Society of the Future? International Journal of Science and Mathematics Education, 15, 105-123. https://doi.org/10.1007/s10763-017-9814-6

Gustiani, I., Widodo, A., \& Suwarma, I. R. (2017). Development and Validation of Science, Technology, Engineering and Mathematics (STEM) based Instructional Material. AIP Conference Proceedings, 1848(May). https://doi.org/10.1063/1.4983969

Hafni, R. N., Herman, T., Nurlaelah, E., \& Mustikasari, L. (2020). The Importance of Science, Technology, Engineering, and Mathematics (STEM) Education to Enhance Students' Critical Thinking Skill in Facing the Industry 4.0. Journal of Physics: Conference Series, 1521(4), 0-7. https://doi.org/10.1088/1742-6596/1521/4/042040

Kan, A., \& Murat, A. (2018). Investigation of Prospective Science Teachers' 21st Century Skill Competence Perceptions and Attitudes toward STEM. International Online Journal of Educational Sciences, 10(4), 251-272. https://www.iojes.net

Kristanto, Y. D., \& Santoso, E. B. (2020). Towards a Mathematics Textbook for Supporting 21st Century Learning: the Student Perspective. Journal of Physics: Conference Series, 1657(1). https://doi.org/10.1088/1742-6596/1657/1/012037

Milaturrahmah, N., Mardiyana, \& Pramudya, I. (2017). Science, Technology, Engineering, Mathematics (STEM) as Mathematics Learning Approach in 21st Century. AIP Conference Proceedings, 1868(August). https://doi.org/10.1063/1.4995151

Nessa, W., Hartono, Y., \& Hiltrimartin, C. (2017). Pengembangan Buku Siswa Materi Jarak pada Ruang Dimensi Tiga Berbasis Science, Technology, Engineering, and Mathematics (STEM) ProblemBased Learning di Kelas X. Jurnal Elemen, 3(1), 1. https://doi.org/10.29408/jel.v3i1.273

Ni, A., Mariani, S., Prabowo, A., Semarang, U. N., Pembelajaran, M., \& Based, P. (2018). Kemampuan Koneksi Matematis dan Entrepreneurship Siswa SMK dalam Model Pembelajaran Project Based Learning. Jenis pendidikan berdasarkan UU. pendidikan umum, kejuruan, akademik, Pendidikan kejuruan merupakan pendidikan menengah yang mempersiapka. November, 100-113.

Puspandari, N., \& Supraman. (2018). Deskripsi Multimedia Pembelajaran Matematika Berbasis STEM untuk Meningkatkan Keterampilan Berpikir Kreatif Siswa SMA Kelas XII. Seminar Nasional Pendidikan Matematika Ahmad Dahlan, 124-130.

Ramli, N. F., \& Talib, O. (2017). Can Education Institution Implement STEM? From Malaysian Teachers' View. International Journal of Academic Research in Business and Social Sciences, 7(3), 2222-6990. https://doi.org/10.6007/IJARBSS/v7-i3/2772 
Retnowati, S., Riyadi, \& Subanti, S. (2020). The Stem Approach: the Development of Rectangular. International Online Journal of Education and Teaching (IOJET), 7(1), 2-15.

Rosikhoh, D., Mardhiyatirrahmah, L., Abdussakir, A., Abtokhi, A., \& Rofiki, I. (2019). Experienced Teachers' Perceptions: Math-Focused Steam Learning. Abjadia, 4(2), 118. https://doi.org/10.18860/abj.v4i2.8123

Setiawaty, S., Imanda, R., Fitriani, H., \& Sari, P. (2019). Pengembangan LKS Sains Berbasis STEM untuk Siswa Sekolah Dasar. Pengembangan LKS Sains Berbasis STEM untuk Siswa Sekolah Dasar, 1, 485-490.

Shernoff, D. J., Sinha, S., Bressler, D. M., \& Ginsburg, L. (2017). Assessing Teacher Education and Professional Development Needs for the Implementation of Integrated Approaches to STEM Education. International Journal of STEM Education, 4(1), 1-16. https://doi.org/10.1186/s40594-017-0068-1

Susilo, H., \& Sudrajat, A., K. (2020). STEM Learning and its Barrier in Schools: the Case of Biology Teachers in Malang City. Journal of Physics: Conference Series, Vol. 1563,(1), 012042. https://doi.org/10.1088/1742-6596/1563/1/012042

Teo, P. (2019). Teaching for the 21st Century: a Case for Dialogic Pedagogy. Learning, Culture and Social Interaction, 21 (March), 170-178. https://doi.org/10.1016/j.lcsi.2019.03.009

Tofel-Grehl, C., \& Callahan, C. M. (2014). STEM High School Communities: Common and Differing Features. Journal of Advanced Academics, 25(3), 237-271. https://doi.org/10.1177/1932202X14539156

Utami, T. N., Jatmiko, A., \& Suherman, S. (2018). Pengembangan Modul Matematika dengan Pendekatan Science, Technology, Engineering, and Mathematics (STEM) pada Materi Segiempat. Desimal: Jurnal Matematika, 1(2), 165. https://doi.org/10.24042/djm.vli2.2388

Winangun, M. M., \& Kurniawan, D. (2019). The Barriers of School Using Subject Design Curriculum in Implementing STEM Education: Perspectives of Science Teacher. ACM International Conference Proceeding Series, 66-70. https://doi.org/10.1145/3341042.3341053 